\title{
HIGH VALUE CARBON MATERIALS FROM PET RECYCLING
}

\author{
J.B. Parra*, C.O. Ania, A. Arenillas, F. Rubiera, J.J. Pis
}

Instituto Nacional del Carbón, CSIC. Apartado 73, 33080 Oviedo (Spain)

*Corresponding author

Tf +34985119090 Fax +34985297662 email jbparra@incar.csic.es

\begin{abstract}
Polyethyleneterephthalate, PET, has become one of the major post-consumer plastic waste. In this work special attention was paid to minimising PET residues and to obtain a high value carbon material. Pyrolysis and subsequent activation of PET from post-consumer soft-drink bottles was performed. Activation was carried out at $925^{\circ} \mathrm{C}$ under $\mathrm{CO}_{2}$ atmosphere to different burn-off degrees. Textural characterisation of the samples was carried out by performing $\mathrm{N}_{2}$ adsorption isotherms at $-196^{\circ} \mathrm{C}$. The obtained carbons materials were mainly microporous, presenting low meso and macroporosity, and apparent BET surface areas of up to $2500 \mathrm{~m}^{2} \mathrm{~g}^{-1}$. The capacity of these materials for phenol adsorption and PAHs removal from aqueous solutions was measured and compared with that attained with commercial active carbons. Preliminary tests also showed high hydrogen uptake values, as good as the results obtained with high-tech carbon materials.
\end{abstract}

KEYWORDS: Carbon Materials, Plastic Waste, Adsorption, $\mathrm{H}_{2}$ storage

\section{INTRODUCTION}

Plastics utilization has grown sharply over the years. Particularly, PET consumption has recorded the fastest growth rate in the global plastic market due to ongoing expansion of the PET bottle market [1]. The usage of polyethylene and PET products, as things stand right now, constitutes a relevant environmentally unsustainable problem. The basic challenge is for PET post-consumer reclamation to keep pace with growing consumption.

The most common ways to deal with PET disposal problems are incineration and chemical recycling [1,2]. Recycling PET waste is increasingly demanded for both ecological and technological reasons. In addition, stricter regulation concerning the recovery of waste is currently coming in force.

In this work, the obtention of a high value carbon material from PET waste was investigated as an alternative to chemical recycling to minimise the even disposal problems. In these lines, the aim of this work was to characterise the carbon products obtained from pyrolysis and subsequent activation in $\mathrm{CO}_{2}$ of PET waste, and to extend the field of the potential applications 
of the final products as adsorbents. In this sense, the capacity of these materials for phenol adsorption and PAHs removal from aqueous solutions was evaluated and compared with that attained with commercial active carbons. On the other hand, preliminary tests on hydrogen uptake were also carried out and compared with those attained in other works more expensive with high-tech carbon materials $[3,4]$.

\section{EXPERIMENTAL}

The experimental procedure followed during PET waste pyrolysis has been previously described [5]. The char obtained -P- was ground, sieved and a particle size fraction of $0.212-$ $0.075 \mathrm{~mm}$ was selected for physical activation with $\mathrm{CO}_{2}$. P char was treated at $925^{\circ} \mathrm{C}$ under nitrogen atmosphere for one hour (sample PC). Then, around $6 \mathrm{~g}$ of the carbon material was activated in $10 \mathrm{~mL} \mathrm{~min}{ }^{-1}$ of $\mathrm{CO}_{2}$ at $925^{\circ} \mathrm{C}$. Samples with different activation degrees (12, 35, 58 and 76\% burn-off) were obtained and denoted as PC12, PC35, PC58 and PC76, respectively.

Textural characterisation was carried out by measuring mercury porosimetry and $\mathrm{N}_{2}$ adsorption isotherms at $-196{ }^{\circ} \mathrm{C}$. Different methods (i.e. BET, Dubinin-Radushkevich, DFT) were applied to the adsorption isotherms

For phenol and PAH adsorption from aqueous solution, columns with $0.5 \mathrm{~g}$ of the carbon materials were employed. The flow rate of the solution $\left(4 \mathrm{~mL} \mathrm{~min}^{-1}\right)$ and the temperature $\left(30^{\circ} \mathrm{C}\right.$ ) were kept constant throughout the adsorption stage. In this work, breakthrough experiments were conducted and analysis of the final concentration of the solutions was done spectrophotometrically (UV-VIS).

\section{RESULTS AND DISCUSSION}

\subsection{Textural characterisation}

By application of the BET method to the $\mathrm{N}_{2}$ adsorption isotherms, the apparent surface area values of the samples were obtained. Table 1 compiles the apparent BET surface areas along with the textural parameters by application of the Dubinin-Radushkevich -DR- equation.

A significant and gradual increase of the apparent BET surface area with the degree of burn-off was observed, reaching values relatively high for the most activated sample PC76. An increase in the micropore volume and the accessible pore width $(\mathrm{L})$ with the burn-off degree was observed.

The pore size distribution (cf. Figure 1) was obtained from the mercury porosimetry data and the DFT method applied to the $\mathrm{N}_{2}$ adsorption isotherms [6]. From mercury porosimetry, it was observed that the samples studied are non macroporous. Only the samples activated with $\mathrm{CO}_{2}$ at high burn-off degrees -PC58 and PC76- present a slight development of large pores. On the other hand, an increase in the volume of narrow micropores with the increase in the degree of burn-off was observed up to $35 \%$ of activation, while volume of the medium-sized 
micropores increases gradually as burn-off increases. This indicates a gradual broadening of the pores with the burn-off degree. The mesoporosity of the samples also increases gradually with the burn-off degree.

\subsection{PAH adsorption from an aqueous solution}

Preliminary tests for the evaluation of the efficiency of these materials for the adsorption of aromatics from liquid phase were carried out, using naphthalene and phenol as probe molecules. The adsorption capacities of the samples studied along with the uptake of commercial activated carbons (Q, CM and F400) are compiled in Table 2. The characteristics of the commercial adsorbents selected can be found in the literature $[7,8]$.

A relationship between the surface area of the activated materials and their adsorption capacities was observed. The most activated the sample is, the higher adsorption capacity was attained. The results obtained for the removal of both phenol and naphthalene comparable to the retention attained with commercial activated carbons. Consequently, samples obtained by pyrolysis and subsequent activation of PET waste showed good properties as adsorbents of organic compounds.

\subsection{Hydrogen adsorption}

One of the possible applications of these materials is hydrogen storage. Hydrogen is currently of great interest because it is the cleanest vector of energy. Although carbon materials have been proposed as a solution for hydrogen storage [9,10], an adequate pore size distribution is necessary to assure a strong interaction with hydrogen at room temperature and at moderate pressures [11].

As a preliminary study of the suitability of the samples obtained from PET waste, for hydrogen storage, $\mathrm{H}_{2}$-adsorption measurements were performed with a Micromeritics ASAP 2000 at $-196{ }^{\circ} \mathrm{C}$ in the pressure range $0-1$ bar. It was observed that adsorption-desorption experiments were reversible, suggesting that $\mathrm{H}_{2}$ uptake path goes through physisorption.

Modelling isotherms is a useful tool in adsorption studies, as practical information (ie. adsorptive capacity) can often be provided. The simplest approach for describing gas adsorption on surfaces is the idealised theory of Langmuir. Therefore, in this work, the $\mathrm{H}_{2}$ adsorption data was fitted to this equation, written in the form:

$$
v=\frac{V_{m} 6 P}{1+6 \mathscr{P}}
$$

where $\mathcal{V}$ is the volume adsorbed $\left(\mathrm{cm}^{3} \mathrm{~g}^{-1}\right), \mathcal{P}$ is the equilibrium pressure (mm $\left.\mathrm{Hg}\right), \quad 6$ is a parameter and $\mathcal{V} m$ is the saturated amount adsorbed corresponding to monolayer coverage.

Table 3 shows the correlation of the experimental data to the Langmuir model. A good correlation was found for all the samples. 
Regarding the hydrogen adsorption capacities, the results obtained for the samples studied in this work are comparable to or, in many cases, better than other results obtained for higher cost carbon materials [12,13].

Furthermore, the apparent BET surface area, and the volume of micropores obtained by the DR method applied to the $\mathrm{N}_{2}$ adsorption isotherms, were correlated to the hydrogen storage capacity at $-196{ }^{\circ} \mathrm{C}$ (Figure 2). The increase of the surface area and micropore volume gives rise to an increase of the $\mathrm{H}_{2}$ adsorption capacity. This suggests that the $\mathrm{H}_{2}$ adsorption on the carbon materials depends primarily on their structural properties. Thus, it seems that hydrogen is basically physisorbed (non-dissociatively adsorbed) on the carbon structure of the samples studied.

The above results also put forward the importance of the pore size distribution in the hydrogen uptake. In this sense, large storage capacities are reached in samples containing a large volume of micropores. Regarding the suitable diameter of the micropores, it was observed that higher uptake is attained on the samples with the largest pore width, given by the $\mathrm{L}$ value (cf. Table 1). Nevertheless, a contribution of the uptake might also be due to the generation of mesoporosity in most activated samples (PC58 and PC76).

Future research will be focused on the optimum pore diameter of carbon materials and its effect on hydrogen uptake.

\section{CONCLUSIONS}

The activation of PET waste produced carbon materials basically microporous, but with a low macroporosity. Considerable mesoporosity is as well developed in highly activated samples, and very high apparent BET surface areas -up to $2468 \mathrm{~m}^{2} \mathrm{~g}^{-1}$ - were achieved.

Preliminary tests on potential applicability of these materials showed that removal of PAH and phenol was highly satisfactory and comparable to the retention attained with commercial activated carbons.

Regarding hydrogen adsorption, carbon materials obtained from plastic waste, showed adsorption capacities higher than those of nanotubes, which are high-cost carbon adsorbents. Thus, carbon materials obtained from PET pyrolysis and activation seem to have textural properties (high surface area and large micropore volume) adequate for hydrogen uptake. Consequently, these samples are good adsorbents for the purposes targeted, although more research has still to be done.

\section{REFERENCES}

[1] Association of plastics manufacturer in Europe, "An analysis of plastics consumption and recovery in Western Europe”, Spring 2001

[2] Mishra S, Goje AS, Zope VS. Polymer Reaction Engineering 2003;11(1):79 
[3] Dresselhaus MS, Williams KA, Eklund PC. MRS Bull. 1999;24(11):45

[4] Tibbetts GG, Meisner GP, Olk CH. Carbon 2001;39(15):2291

[5] Parra JB, Ania CO, Arenillas A, Pis JJ. Stud. Surf. Sci. Cat. 2002;144:537

[6] Olivier J. Carbon 1998;36:1469

[7] Gustafson KE, Dickhut RM, J.Chem Eng. Data. 1994;39(2):281

[8] Ania CO, Parra JB, Pis JJ. Fuel Process. Technol. 2002;77-78:337

[9] Darkim FL, Malbrunot P, Tartaglia GP. Int. J. Hydrogen Energy 2002;27:193

[10] Chen X, Weglikowska UD, Haluska M, Hulman M, Roth S. Mat. Res. Soc. Symp. Proc. 2002;706(Z9):11

[11] Dillon AC, Heben MJ. Applied Physics A Mat. Sci. Proc. 2001;72:133

[12] Chahine R, Bénard P, IEA. Ed. Sandrock G. SunaTech Inc. 2001;104-107

[13] Nijkamp MG, Raaymakers JEMJ, van Dillen AJ, de Jong KP. Applied Physics A Mat. Sci.Proc. 2001;72:619 
Table 1. Textural parameters obtained from $\mathrm{N}_{2}$ adsorption isotherms and the BET and DR equations

\begin{tabular}{lccccc}
\hline & & \multicolumn{4}{c}{$\mathrm{DR}$} \\
\cline { 3 - 6 } Sample & $\begin{array}{c}\mathrm{S}_{\text {BET }} \\
\left(\mathrm{m}^{2} \mathrm{~g}^{-1}\right)\end{array}$ & $\begin{array}{c}\mathrm{W}_{0} \\
\left(\mathrm{~cm}^{3} \mathrm{~g}^{-1}\right)\end{array}$ & $\begin{array}{c}\mathrm{E}_{0} \\
\left(\mathrm{~kJ} \mathrm{~mol}^{-1}\right)\end{array}$ & $\begin{array}{c}\mathrm{L} \\
(\mathrm{nm})\end{array}$ & $\begin{array}{c}\mathrm{S}_{\text {mic }} \\
\left(\mathrm{m}^{2} \mathrm{~g}^{-1}\right)\end{array}$ \\
\hline PC12 & 668 & 0.25 & 27.8 & 0.66 & 629 \\
PC35 & 1405 & 0.52 & 21.8 & 1.04 & 909 \\
PC58 & 1920 & 0.67 & 19.0 & 1.42 & 930 \\
PC76 & 2468 & 0.90 & 16.3 & 2.19 & 870 \\
\hline
\end{tabular}

Table 2. Phenol and naphthalene adsorption capacities obtained from breakthrough curves

\begin{tabular}{cccc}
\hline & & $\begin{array}{c}\text { Adsorption Capacity } \\
\left(\mathrm{mg} \mathrm{g}^{-1}\right)\end{array}$ \\
\cline { 3 - 4 } Sample & $\begin{array}{c}\text { BET } \\
\left(\mathrm{m}^{2} \mathrm{~g}^{-1}\right)\end{array}$ & Phenol $^{\text {a }}$ & Naphthalene $^{\mathrm{b}}$ \\
\hline PC12 & 668 & 125 & 24 \\
PC35 & 1405 & 200 & 26 \\
PC58 & 1920 & 239 & 27 \\
PC76 & 2468 & 291 & 28 \\
\hline Q & 1149 & 289 & 30 \\
CM & 849 & 263 & 24 \\
F400 & 1164 & 346 & 33 \\
\hline
\end{tabular}

a , solution of phenol (2000 ppm)

b, saturated solution of naphthalene (30 ppm)

Table 3. Langmuir parameters and $\mathrm{H}_{2}$ adsorption capacities at $-196{ }^{\circ} \mathrm{C}$ for the samples studied

\begin{tabular}{cccccc}
\hline Sample & $\begin{array}{c}\mathcal{V} m \\
\left(\mathrm{~cm}^{3} \mathrm{~g}^{-1}\right)\end{array}$ & 6 & $\mathrm{r}^{2}$ & $\begin{array}{c}\mathcal{V} m \\
(\mathrm{wt} \%)\end{array}$ & $\begin{array}{c}\mathrm{H}_{2} \\
(\mathrm{wt} \%)\end{array}$ \\
\hline PC12 & 176 & 0.010 & 0.999 & 1.6 & 1.4 \\
PC35 & 248 & 0.007 & 0.998 & 2.2 & 1.9 \\
PC58 & 309 & 0.004 & 0.999 & 2.8 & 2.1 \\
PC76 & 355 & 0.003 & 0.999 & 3.2 & 2.3 \\
\hline
\end{tabular}


Fig. 1. Pore size distribution of the samples studied using the DFT method and mercury porosimetry.

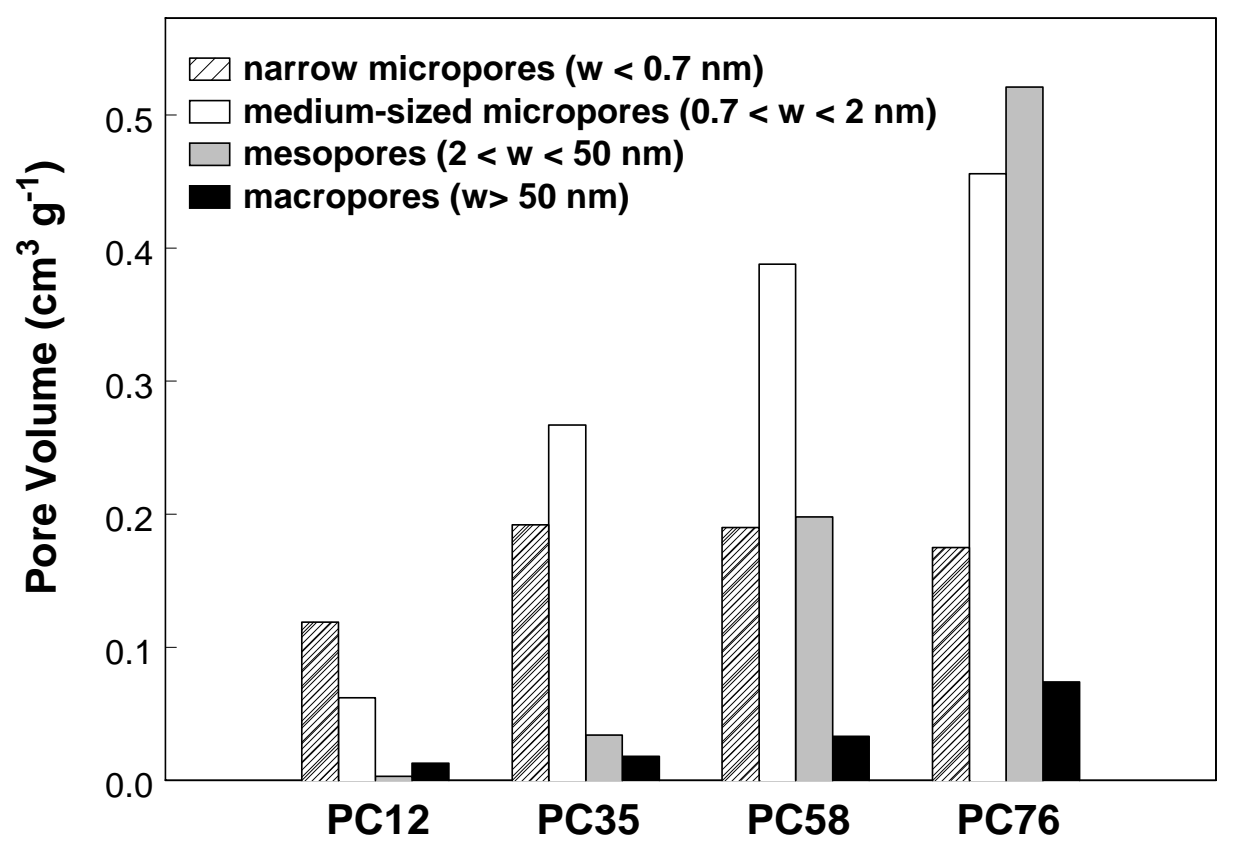


Fig. 2. Correlation of $\mathrm{H}_{2}$ adsorption capacity with apparent BET surface area and micropore volume $\mathrm{W}_{\mathrm{o}}$.

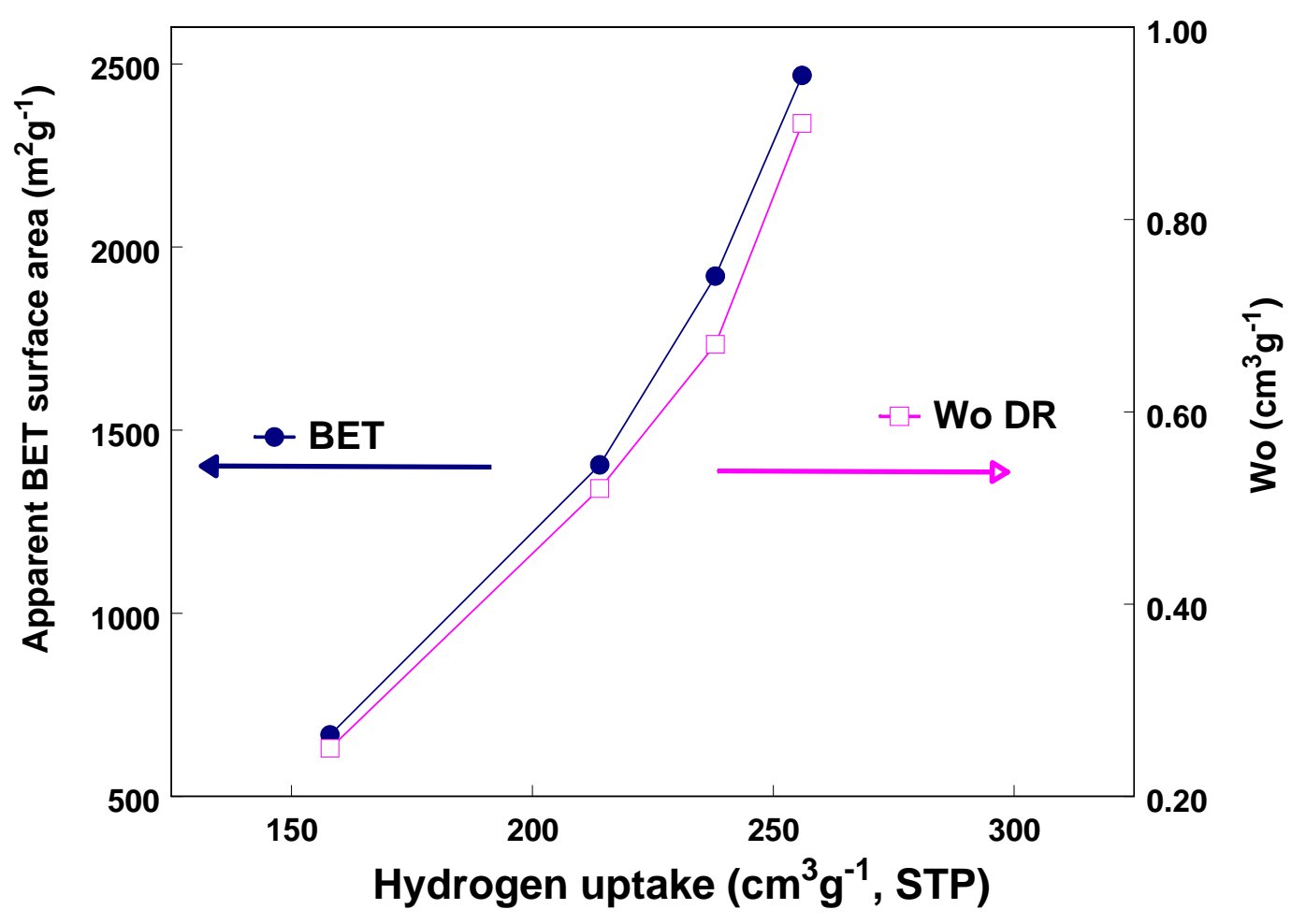

